\title{
Squamous Papilloma of the Buccal Mucosa with Oral Submucous Fibrosis
}

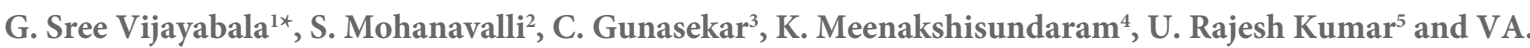 \\ Janagarathinam ${ }^{6}$

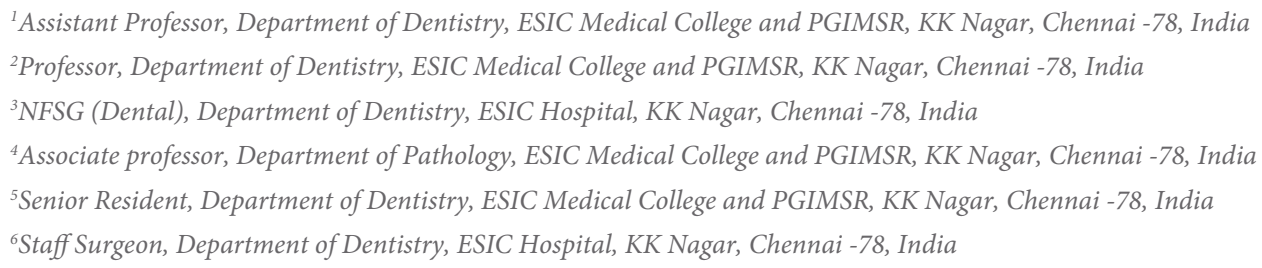

*Corresponding author: Dr. G. SreeVijayabala, MDS, Assistant Professor, Department of Dentistry, ESIC Medical College and PGIMSR, KK Nagar, Chennai -78, India, Tel: 9543848504; E-mail: dr.svbala@gmail.com

Received: 16 March, 2015; Accepted: 20 April, 2015; Published: 22 April, 2015

Squamous Papilloma of the buccal mucosa with Oral Submucous Fibrosis

The squamous papilloma is a common benign oral epithelial neoplasm [1]. Papilloma usually presents as an exophytic, painless papillary mass [2]. Oral Submucous Fibrosis is a premalignant condition [3]. A 45 year old female patient presented with growth in inner side of left cheek region. Patient had history of gutka chewing for past 6 years. On intra oral examination, the growth was pinkish, strawberry like in appearance with a papillary surface in the right buccal mucosa (Figure 1). Generalized blanching of oral mucosa was present (Figure 2). The growth was not tender on palpation and firm in consistency. The growth was pedunculated with no induration or bleeding on palpation. Palpable fibrotic bands were present in the buccal mucosa. The patient was provisionally diagnosed to have papilloma of right buccal mucosa with oral submucous fibrosis. A differential diagnosis of verruca vulgaris, verrucousleukoplakia and condylomaaccuminatum was considered. After investigations, the patient was subjected to excisional biopsy. Excisional biopsy of the

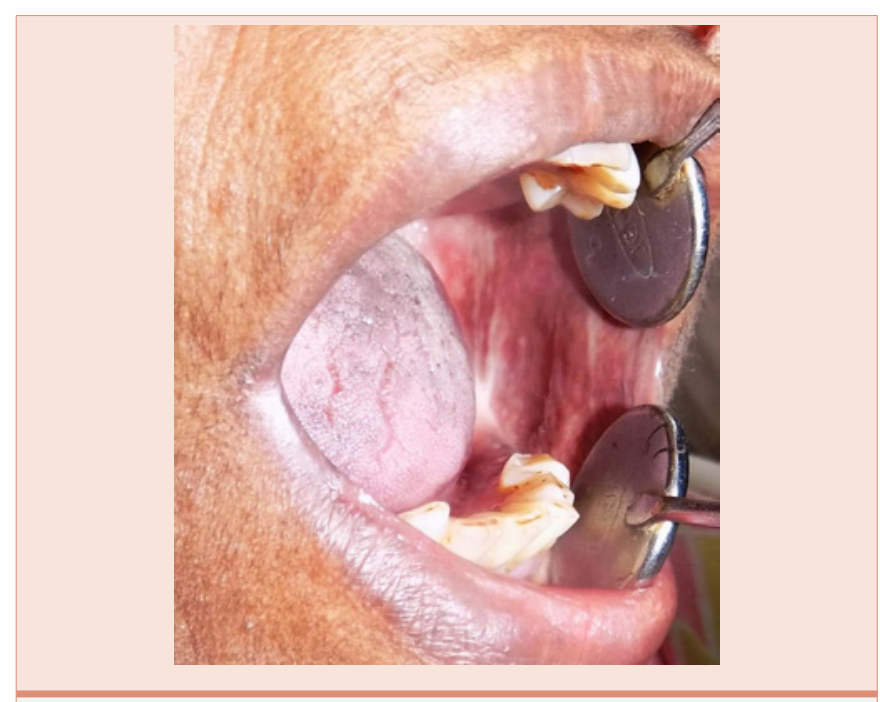

Figure 2: Oral Submucous Fibrosis presenting as generalised blanching of oral mucosa with palpable fibrotic bands in buccal mucosa.

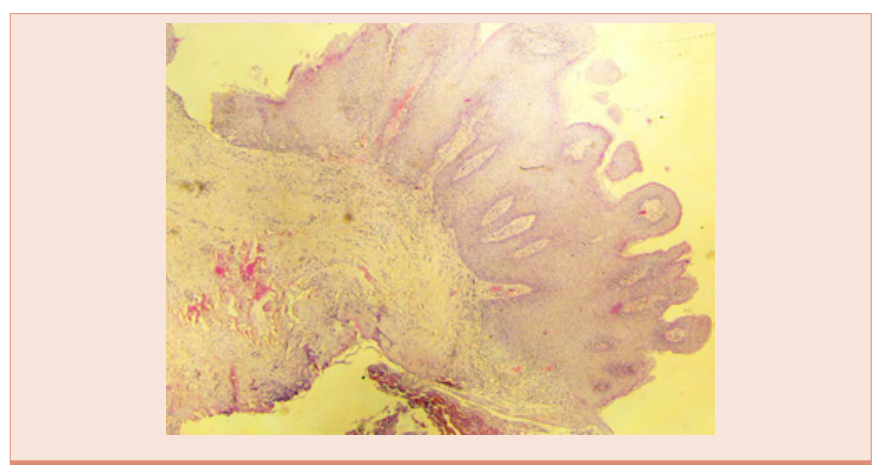

Figure 3: Hyperplasticstratified squamous epithelium with a fibrovascular core. 
growth revealed papillae lined by hyperplastic stratified squamous epithelium with a fibrovascular core and the diagnosis of squamous papilloma was confirmed histopathologically (Figure 3).

\section{References}

1. Naik R, Nithin KP, Mujib BR, Rai KK (2014) An Unusual Presentation of Squamous Papilloma on the Buccal Mucosa. Indian Journal of Multidisciplinary Dentistry 4: 1015-18.
2. Neville BW, Damm DD, Allen CM, Bouquot JE (2009) Oral and maxillofacial pathology. $3^{\text {rd }}$ ed. Philadelphia. Elsevier p362-63.

3. Auluck A, Rosin MP, Zhag L, Sumanth KN (2008) Oral Submucous Fibrosis, a Clinically Benign but Potentially Malignant Disease: Report of 3 Cases and Review of the Literature. J Can Dent Assoc 74: 735-40. 